\title{
Numerical Analysis of Flow Field and Heat Transfer of 2D Wavy Ducts and Optimization by Entropy Generation Minimization Method
}

\author{
Ouldouz Nourani Zonouz and Mehdi Salmanpour \\ Department of Mechanical Engineering, Marvdasht Branch, Islamic Azad University, Marvdasht 73711-13119, Iran \\ Correspondence should be addressed to Ouldouz Nourani Zonouz, o_nourani@yahoo.com
}

Received 2 July 2011; Revised 10 November 2011; Accepted 13 November 2011

Academic Editor: Felix Sharipov

Copyright (C) 2012 O. Nourani Zonouz and M. Salmanpour. This is an open access article distributed under the Creative Commons Attribution License, which permits unrestricted use, distribution, and reproduction in any medium, provided the original work is properly cited.

This article provided a research for the trend of heat transfer and flow field through a 2-dimensional wavy duct. To construct a grid mesh, the physical domain was transferred to the computational domain and finite volume scheme was used for discretizing the governing equations. Through the simulation, the flow regime stayed in laminar mode. Constant temperature boundary condition has been used for solid walls. Air was used as a working fluid. Existence of waves makes some phenomenon like flow separation. Effect of Reynolds number, wave width, and wave number has been analyzed and velocity distribution, heat transfer coefficient, and tangential stress were computed for different cases. The final results were compared with the same straight duct. The entropy generation minimization method has been used for better comparison between final results.

\section{Introduction}

For many industrial thermal systems, there is much interest in reducing fuel consumption and/or increasing of system efficiency. For gas turbine recuperators, an efficient heat exchanger is required to reduce the system size and increase the cycle efficiency. The heat exchangers generally contain flow channels with various cross-sectional shapes which are corrugated and wavy curved in the mainstream to enhance heat/mass transfer rates by generating secondary flow. The heat transfer and flow characteristics in the channel with wavy plates have been widely studied previously. Sunden and Trollheden [1] studied on the heat transfer and pressure drop in the corrugated channels and the smooth tubes under constant heat flux conditions. Nishimura and Matsune [2] simulated and visualized the dynamical behavior of vortices flow in channels. Fabbri and Rossi $[3,4]$ studied the laminar convective heat transfer in the smooth and corrugated channels. Cheng and Wang [5] studied on the forced convection of micropolar fluid flow over the wavy surfaces. Ergin et al. [6] numerically studied periodic flow through a corrugated duct. Vasudevaiah and Balamurugan
[7] studied the heat transfer in a corrugated microchannel under constant heat flux conditions. Niceno and Nobile [8] on the two-dimensional fluid flow and heat transfer in the periodic and wavy channels. Ali and Hanaoka [9] considered effects of the operating parameters on laminar flow forced-convection heat transfer of air flowing in a channel having a V-corrugated upper plate. Zimmerer et al. [10] studied effects of the inclination angle, the wave length, the amplitude, and the shape of the corrugation on the heat and mass transfer of the heat exchanger. Guzman and Amon [11-13] performed numerical investigations for high transitional Reynolds numbers in converging-diverging (symmetric wavy wall) channels. Wang and Chen [14] determined the heat transfer rates flowing through a sinusoidally curved converging-diverging channel. Savino et al. [15] studied effect of aspect ratio on convection heat transfer enhancement in the wavy channels. Hossain and Islam [16] numerically studied on the fully unsteady fluid flow and heat transfer in sine shaped wavy channels. Metwally and Manglik [17] simulated the laminar periodically developed forced convection in sinusoidal corrugated- plate channels by using the control volume finite-difference method. Naphon 


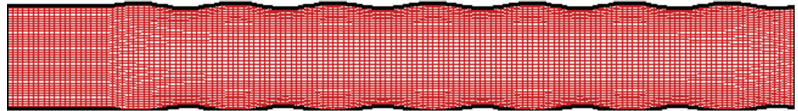

FIgURE 1: Geometry of the duct $(A=0.001, b=0.125)$.

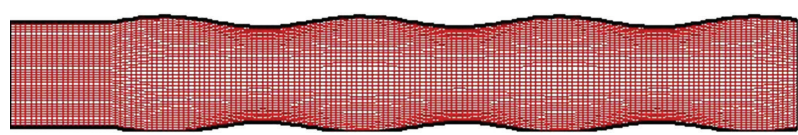

Figure 2: Geometry of the duct $(A=0.002, b=0.25)$.

[18-20] experimentally and numerically studied on the heat transfer characteristics and pressure drop in the corrugated channel with different wavy angles and channel heights. Gradeck et al. [21] observed flow patterns of a gas-liquid flow and analyzed heat transfer in horizontal corrugated channels by using nitrogen and water as working fluids. Islamoglu et al. [22-24] numerically and experimentally studied the effect of the channel height on the enhancement of the heat-transfer characteristics in a corrugated heat-exchanger channel. In addition, artificial networks were employed to analyze the heat transfer in corrugated channels. Kuhn and Rohr [25] employed digital particle image velocimetry and planar laser-induced fluorescence techniques to examine the spatial variation of the streamwise and normal velocity components at the heated wavy surface. Chang et al. [26, 27] studied the heat transfer and pressure drop in furrowed channels with transverse sinusoidal wavy walls. Pham et al. [28] have been using large eddy simulation with dynamic modeling to investigate three-dimensional turbulent flow in wavy channels. Sui et al. [29] did some works in wavy microchannels. They simulated numerically laminar liquid-water flow and heat transfer in three-dimensional microchannels with rectangular cross section.

\section{Geometry}

The principle aim of this article is to improve the rate of the heat transfer thorough 2-dimensional ducts. A fully developed flow enters the duct and passes a short length with straight walls; this part reduces the effect of the entrance region. Then, the fluid flow enters the second region with wavy geometry. This sudden change in geometry made some variations for rate of heat transfer.

Figures 1 and 2 illustrate the complete geometry of problem schematically. The length of the duct is $30 \mathrm{~cm}$ and the width of the duct is $4 \mathrm{~cm}$. A length of $4 \mathrm{~cm}$ from beginning of the duct is flat and a function like $y=$ $A \sin (x /(L * b))$ is defined to the rest of the duct. In this function, $A$ represents the height of the wave, $L$ is the length of the duct and by changing the value of $b$, number of waves will be changed.

Reynolds number was defined as $\operatorname{Re}=\rho U_{\text {in }} D_{h} / \mu$. The hydraulic diameter is twice the entrance diameter.

\section{Governing Equations}

The combination of continuity, Navier-Stokes and energy equations in 2-dimensional and steady form was used as the essential governing equations. These equations and their boundary conditions are listed through numbers of 1 to 6 .

Continuity.

$$
\frac{\partial}{\partial x}(\rho u)+\frac{\partial}{\partial y}(\rho v)=0 .
$$

Momentum Equation in x-Direction.

$$
\left[\frac{\partial}{\partial x}(\rho u u)+\frac{\partial}{\partial y}(\rho v u)\right]=-\frac{\partial P}{\partial x}+\left[\frac{\partial}{\partial x}\left(\mu \frac{\partial u}{\partial x}\right)+\frac{\partial}{\partial y}\left(\mu \frac{\partial u}{\partial y}\right)\right] .
$$

\section{Momentum Equation in y-Direction.}

$$
\left[\frac{\partial}{\partial x}(\rho u v)+\frac{\partial}{\partial y}(\rho v v)\right]=-\frac{\partial P}{\partial y}+\left[\frac{\partial}{\partial x}\left(\mu \frac{\partial v}{\partial x}\right)+\frac{\partial}{\partial y}\left(\mu \frac{\partial v}{\partial y}\right)\right] .
$$

Energy Equation.

$$
\begin{aligned}
{\left[\frac{\partial}{\partial x}\left(\rho C_{p} u T\right)+\frac{\partial}{\partial y}\left(\rho C_{p} v T\right)\right]=} & {\left[\frac{\partial}{\partial x}\left(k \frac{\partial T}{\partial x}\right)+\frac{\partial}{\partial y}\left(k \frac{\partial T}{\partial y}\right)\right] } \\
& +\mu\left[\left(\frac{\partial u}{\partial y}\right)^{2}+\left(\frac{\partial v}{\partial x}\right)^{2}\right]
\end{aligned}
$$

Inlet Boundary Conditions.

$$
\begin{gathered}
T_{\text {inlet }}=300 \mathrm{~K}, \\
u=-6 u_{\text {inlet }}\left[\left(\frac{y}{h_{\text {ave }}}\right)^{2}-\left(\frac{y}{h_{\text {ave }}}\right)\right], \\
v=0 \\
\operatorname{Pr}=0.7 .
\end{gathered}
$$

Wall Boundary Conditions.

$$
\begin{gathered}
T_{\text {up }}=400 \mathrm{~K}, \\
T_{\text {down }}=400 \mathrm{~K}, \\
u=v=0 .
\end{gathered}
$$

In above equations $h_{\text {ave }}$ is the distance between the up and down plates and equal to the entrance diameter. To descritize the above equations finite volume method was used. Reynolds number, number and the width of waves were changed. For each case some graphs like Nusselt number, rate of heat transfer and stress distribution were sketched. 


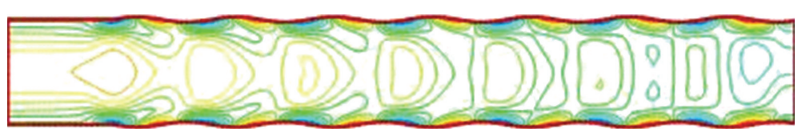

FIgURE 3: Velocity distribution $(\mathrm{Re}=300)$.

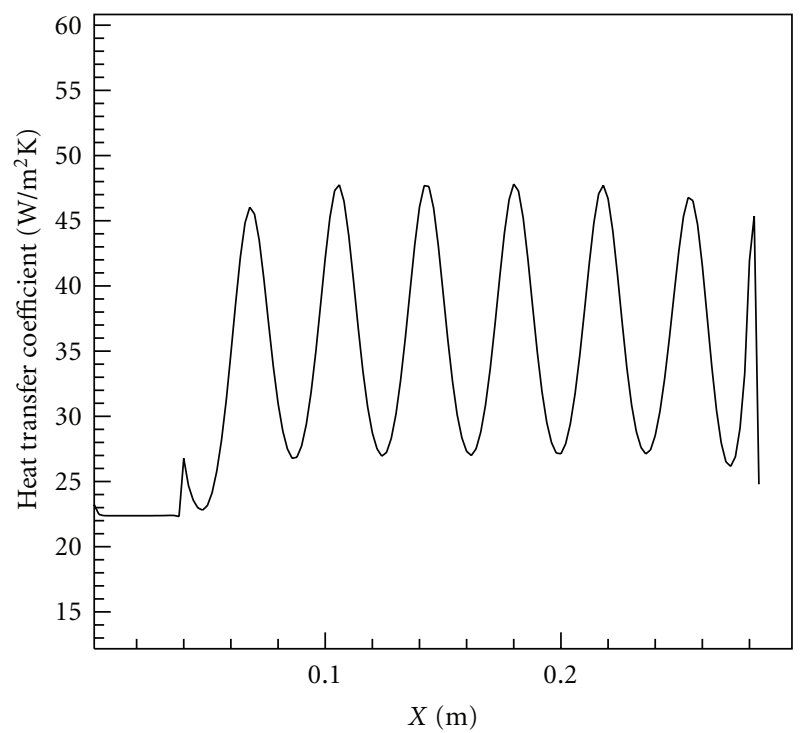

FIGURE 4: Heat transfer coefficient distribution along the wall $(\mathrm{Re}=$ $300)$.

\section{Results}

Three characteristic parameters like Reynolds number, number of waves, and the width of the waves have been analyzed in this research. Figure 3 illustrates the velocity distribution along the duct for Reynolds number 300. After passing the flat part of the duct, the flow enters the wavy region and senses a sudden expansion which produces wakes in concave part of waves. Before releasing these wakes from the solid walls, they act as barriers between the wall and the flow stream; hence, the fluid could not sense the hot walls and the heat transfer mechanism will be so weak. In convex part of waves, the flow velocity increases; hence the rate of heat transfer will be raised in these parts (Figure 4). This graph is divided into 2 regions. In the first region, the shape of the duct is straight and the flow is fully developed; hence the trend of graph is approximately constant. In the second region, the heat transfer coefficient finds a wavy trend because of the shape of the duct. From this graph, we can judge that the average heat transfer coefficient in second region is nearly 1.5 times of first region which means better and more powerful heat transfer mechanism.

4.1. Effect of Reynolds Number. Reynolds number is one of the most important parameter through the flow field. By increasing the value of this parameter, the velocity gradient near the solid wall will be increased and causes the separation phenomenon happened with delay. The size of the produced wakes in concave parts of the waves will be much smaller

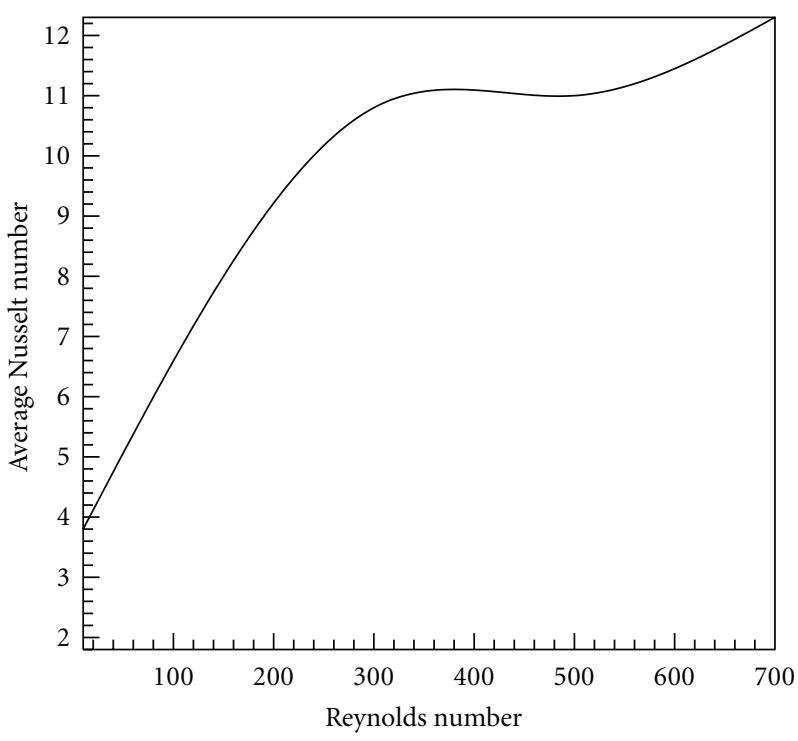

Figure 5: Average Nusselt number distribution versus Reynolds number.

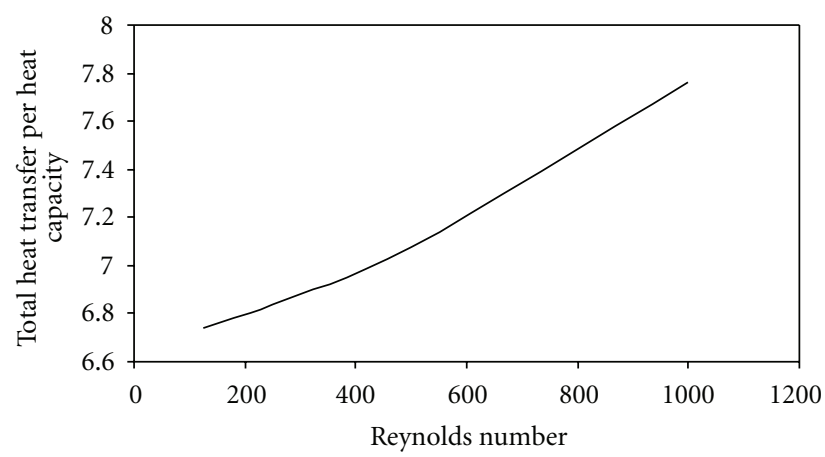

Figure 6: Total heat transferred by flow per heat capacity $\dot{Q}_{\text {total }} / \dot{m} c_{P}$ versus Reynolds number.

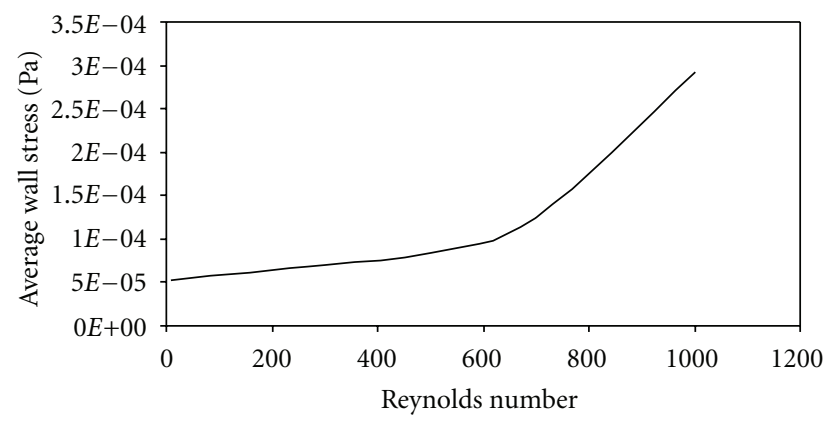

FIGURE 7: Average friction stress along the solid boundary versus Reynolds number.

by increasing the magnitude of the Reynolds number. This reduction in wake's size increases the rate of heat transfer between the fluid stream and the walls of the duct. In this study, the flow field has been studied steadily and the vortexes were not allowed to enter the flow; hence the vortexes act as barriers near the wall. With increasing the Reynolds number, the size of these barriers will be reduced. 


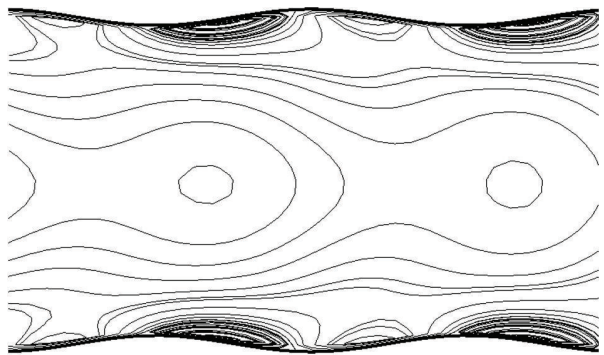

(a)

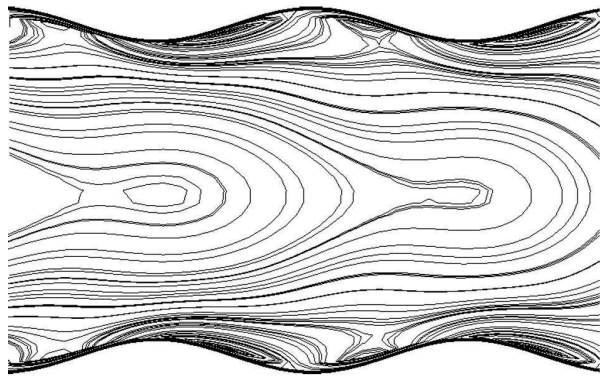

(b)

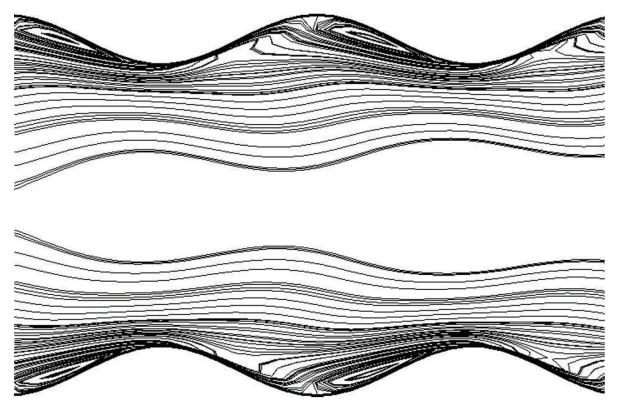

(c)

FIgURe 8: Profile of velocity in third wave for different widths: (a) $A=0.001$, (b) $A=0.002$, (c) $A=0.003$.

In Figure 5, the distribution of average Nusselt number along the wall of duct has been sketched for different Reynolds numbers. By increasing the Reynolds number, the value of dimensionless heat transfer coefficient will be raised which means better heat transfer mechanism. To complete this reason, the quantity of heat which transferred by fluid flow through the same duct has been illustrated for different Reynolds numbers in Figure 6. This figure has the same trend.

Distribution of tangential stress along the wall has been sketched in Figure 7. This graph has a raising trend which means by increasing the Reynolds number, the gradient of velocity near the wall will be increased so; the magnitude of stress will be also raised.

4.2. Effect of Wave Width. Analysis of effect of wave width is one of the most important parameters for improving the quality of heat transfer. Assume a sinus correlation like $y=A \sin (y /(L * b))$ for duct geometry. By increasing the value of $A$ which controls the width of the wave, the edges of wavy region find more sharp shape which causes the diameter of the duct in convex parts reduced. This reduction causes the velocity of the flow and also the rate of heat transfer increases considerably. Figure 8 illustrates the change of velocity profile in same place and same Reynolds number for different widths.

Figure 9 illustrates the trend of heat transfer coefficient along the wall of duct for different widths. This graph predicts that by increasing the width of the wave the magnitude of the heat transfer maximum points raised considerably.

Average Nusselt number distribution for different $A$ coefficient is sketched in Figure 10. The value of average Nusselt number increases with increase of this parameter.

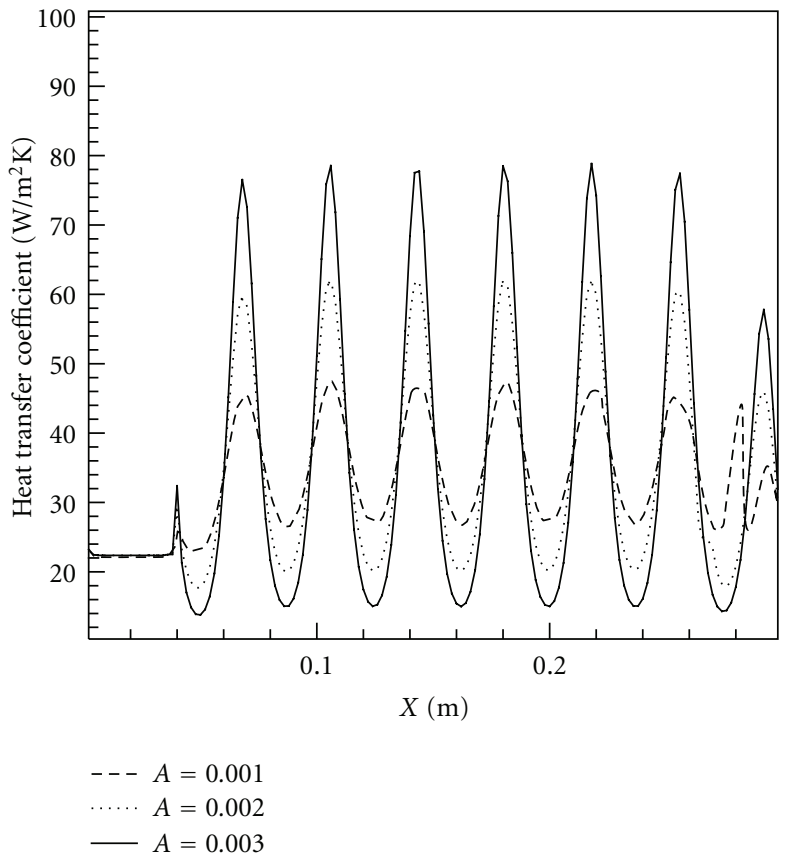

FIGURE 9: Heat transfer coefficient distributions along the length of the duct for different widths $(\mathrm{Re}=300)$.

4.3. Effect of Wave Number. Number of produced waves along the duct has been studied. Figure 11 illustrates the distribution of heat transfer coefficient for different wave number. This figure shows that if the flow senses more waves along its path, the value of heat transfer coefficient will be more significant. 


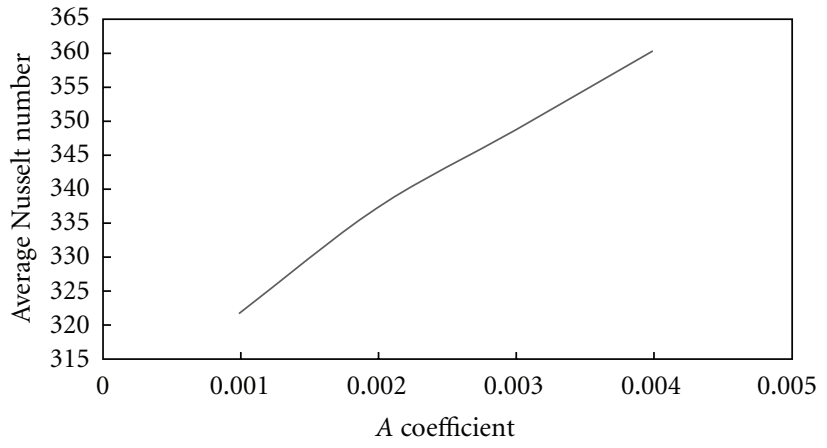

Figure 10: Average Nusselt number distribution versus $A$ coefficient $(\operatorname{Re}=300)$.

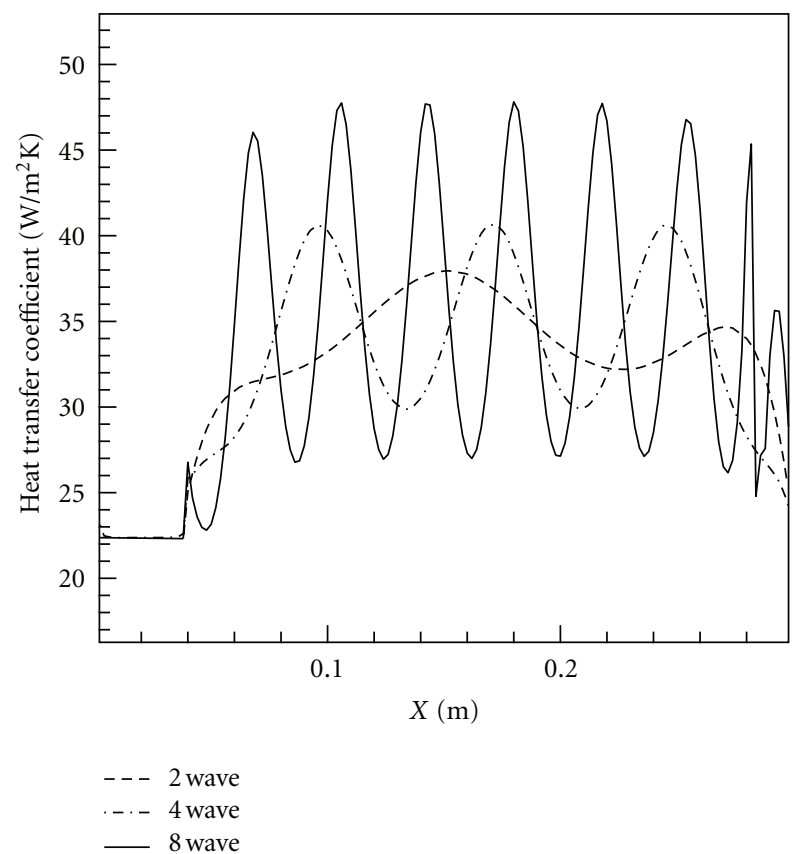

Figure 11: Heat transfer coefficient distribution along the duct for three cases: 2 , 4 , and 8 waves $(\operatorname{Re}=300)$.

\section{Entropy Generation Minimization Method}

One of the newest methods for comparing and optimizing the results is entropy generation method. This method based on the rate of entropy generation. By minimizing the value of this property, the apparatus will work better and more optimize. Term of entropy generation is a summation of conductive heat transfer irreversibility and viscous dissipation which is produced from motion of fluid. By using classic thermodynamic relations, this term can be found in dimensional form. The mass conservation principle, the first and second laws are used to derive the entropy generation term:

$$
\begin{gathered}
\frac{\partial \rho}{\partial t}=-\rho \nabla \cdot V, \\
\rho \frac{\partial i}{\partial t}=-\nabla \cdot q-P \nabla \cdot V-w^{\prime \prime \prime}, \\
\dot{s}_{\mathrm{gen}}=\rho \frac{\partial s}{\partial t}+\nabla \cdot\left(\frac{q}{T}\right) \geq 0 .
\end{gathered}
$$

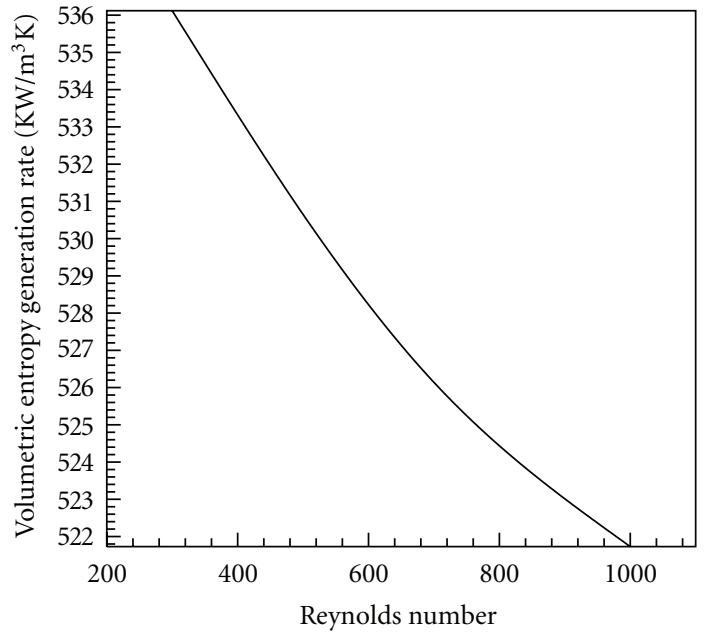

FIGURE 12: Total volumetric entropy generation rate distribution versus Reynolds number.

Eliminating $i$ and $s$ between these laws and using the Gibbs equation

$$
\frac{\partial i}{\partial t}=T \frac{\partial s}{\partial t}+\frac{P}{\rho^{2}} \frac{\partial \rho}{\partial t}
$$

yield the general two-term expression for the volumetric rate of entropy generation:

$$
\dot{s}_{\text {gen }}=-\frac{1}{T^{2}} q \cdot \nabla T-\frac{w^{\prime \prime \prime}}{T} \geq 0 .
$$

By substituting $\left(-w^{\prime \prime \prime}\right)$ with $\mu \phi$ and using Fourier law:

$$
q=-k \nabla T,
$$

the entropy generation equation will be derived:

$$
\dot{s}_{\text {gen }}=\frac{k}{T^{2}}(\nabla T)^{2}+\frac{\mu}{T} \phi \geq 0
$$

or

$$
\begin{aligned}
\dot{s}_{\text {gen }}= & \frac{k}{T^{2}}\left[\left(\frac{\partial T}{\partial x}\right)^{2}+\left(\frac{\partial T}{\partial y}\right)^{2}\right] \\
& +\frac{\mu}{T}\left[2\left(\frac{\partial u}{\partial x}\right)^{2}+2\left(\frac{\partial v}{\partial y}\right)^{2}+\left(\frac{\partial u}{\partial y}+\frac{\partial v}{\partial x}\right)^{2}\right] .
\end{aligned}
$$

For measuring the effect of heat transfer irreversibility and viscous dissipation in magnitude of entropy production, the Bejan number can be defined as

$$
\mathrm{Be}=\frac{\left(k / T^{2}\right)\left[(\partial T / \partial x)^{2}+(\partial T / \partial y)^{2}\right]}{\dot{s}_{\text {gen }}} .
$$

Effect of Reynolds number, wave width, and wave number on the rate of entropy generation and Bejan number has been studied.

By increasing Reynolds number, the velocity and temperature gradients will be increased and the profiles of these 


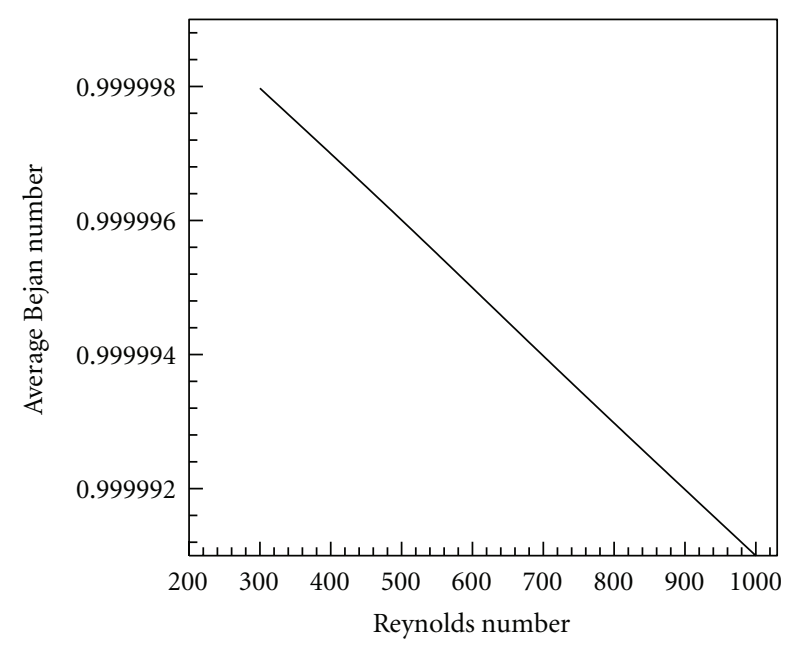

Figure 13: Average Bejan number distribution versus Reynolds number.

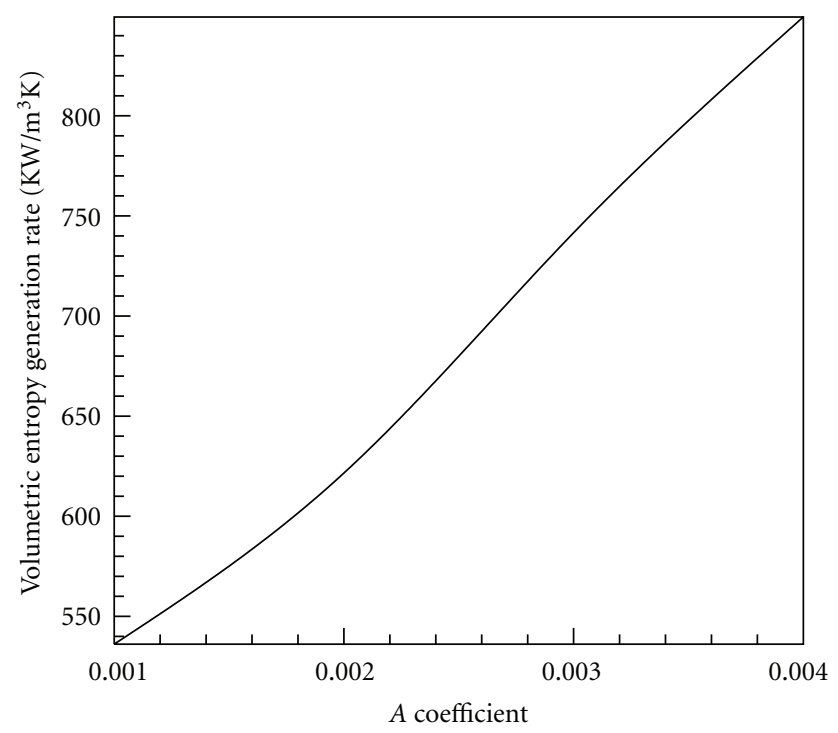

FIgURe 14: Total Volumetric entropy generation rate distribution versus $A$ coefficient $(\operatorname{Re}=300)$.

properties will be more flat; hence, the rate of entropy generation will be decreased. This trend has been illustrated in Figure 12.

Figure 13 shows the trend of average Bejan number versus Reynolds number. By increasing the Reynolds number, the value of Bejan number will be decreased.

Wave width is another parameter which affects the rate of entropy generation. Figure 14 illustrates the trend of total entropy generation versus wave width. By increasing the width of the wave, the rate of entropy generation or dissipation is increased.

By changing the $A$ coefficient, variation of Bejan number is negligible (Figure 15).

By increasing number of waves, the fluid flow senses more viscous dissipation and so the magnitude of entropy generation is raised. This trend is illustrated in Figure 16.

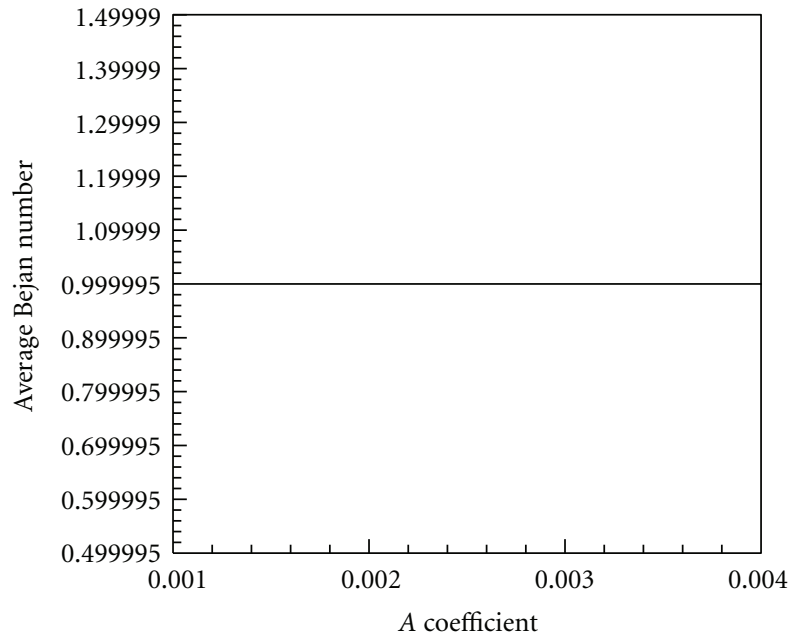

Figure 15: Average Bejan number distribution versus $A$ coefficient $(\operatorname{Re}=300)$.

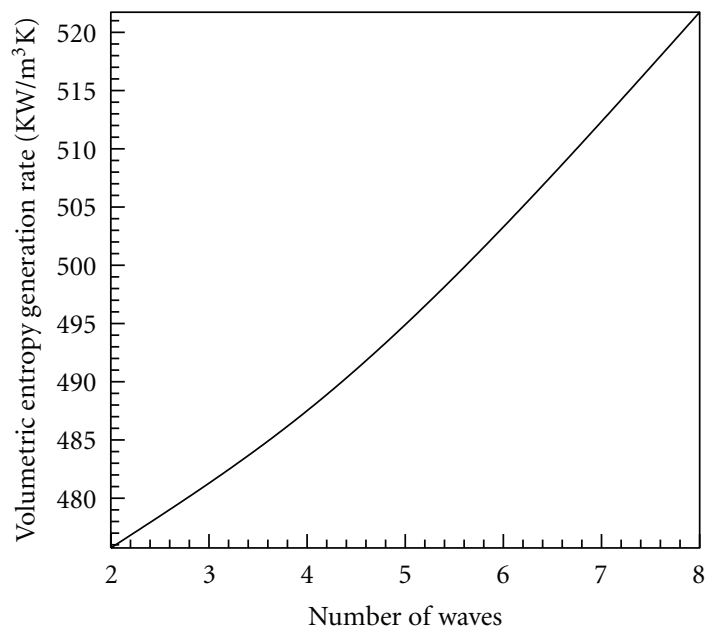

FIgURE 16: Total volumetric entropy generation rate distribution versus number of waves $(\operatorname{Re}=1000)$.

Changing of wave's number has a very small effect on the variation of Bejan number; hence, the distribution of this parameter has a constant trend (Figure 17).

\section{Comparison with Flat Duct}

For comparison, a flat duct with same length and width was selected. Same thermal boundary conditions were considered. Figure 18 shows the trend of Nusselt number for two ducts. In case of wavy duct, the value of averaged Nusselt number is more than the flat duct and this parameter increases with Reynolds number; hence, with producing waves in a duct the rate of heat transfer will be increased.

\section{Conclusion}

Numerical analysis of flow field and heat transfer of 2D wavy ducts and optimization by entropy generation method 


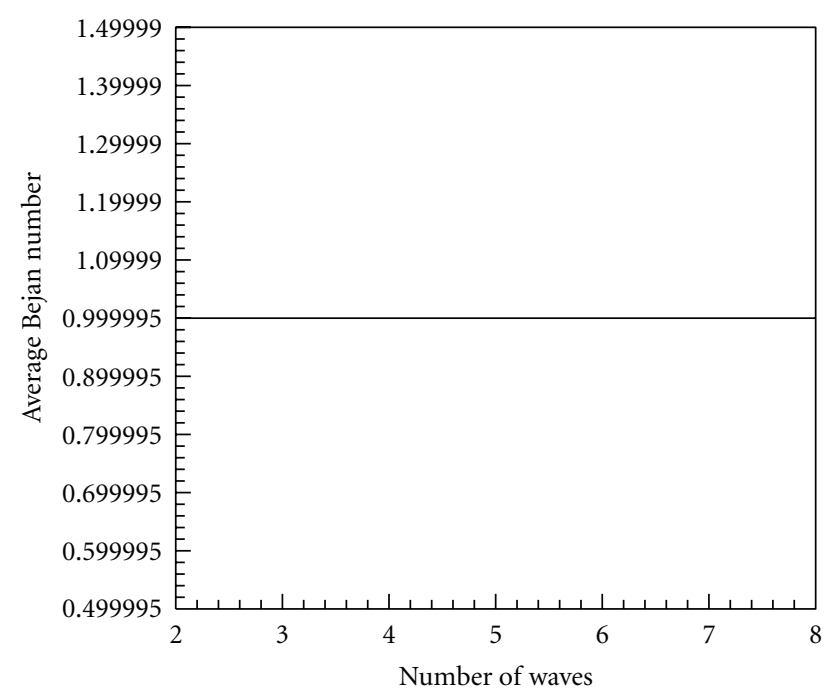

FIgURE 17: Average Bejan number distribution versus number of waves $(\operatorname{Re}=1000)$.

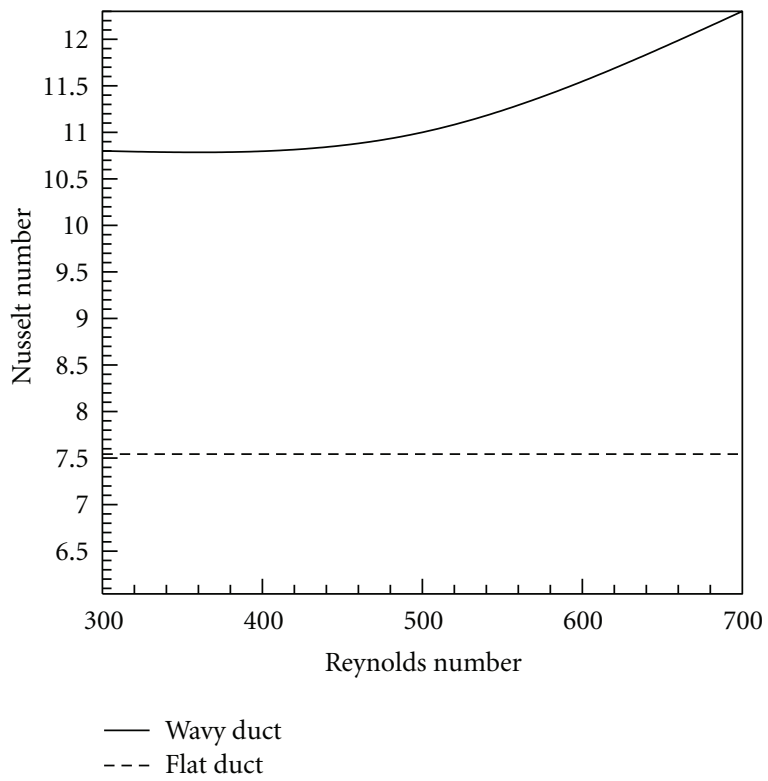

FIGURE 18: Average Nusselt number distributions versus Reynolds number for flat and wavy channels.

has been studied in this research. The governing equations with their boundary conditions were discretized with finitevolume method. The effect of Reynolds number, wave width, and the number of produced waves were obtained. The results show that by increasing Reynolds number, the value of Nusselt number will be increased. Also, by making the waves to be sharper, the heat transfer mechanism will be more powerful and the average Nusselt number will be increased along the length of the duct. The third parameter which was studied is number of waves. With increasing the number of waves, the flow will be passed more concave and convex parts; hence, the rate of heat transfer will be increased. The obtained results were analyzed by entropy generation minimization method. The volumetric entropy generation rate was reduced with increasing the Reynolds number, but in the case of wave width and the number of waves, the value of this property will be increased. In all cases, the value of Bejan number is near one, which means through the laminar flow, the term of the viscous dissipation has a negligible effect.

\section{Nomenclature}

Be: Bejan number

$C_{p}$ : Constant pressure specific heat $(\mathrm{J} / \mathrm{Kg} \mathrm{K})$

$D_{h}$ : Hydraulic diameter $(\mathrm{m})$

$i$ Internal energy $(\mathrm{J} / \mathrm{Kg})$

$K$ : Conductivity $(\mathrm{W} / \mathrm{m} \mathrm{K})$

$L: \quad$ Length of the duct (m)

Nu: Nusselt number

$P$ : $\quad$ Pressure $(\mathrm{Pa})$

Pr: Prandtl number

q: Heat flux $\left(\mathrm{W} / \mathrm{m}^{2}\right)$

Re: Reynolds number

$s: \quad$ Entropy $(\mathrm{J} / \mathrm{Kg} \mathrm{K})$

$\dot{s}_{\text {gen }}$ : Volumetric entropy generation rate $\left(\mathrm{W} / \mathrm{m}^{3} \mathrm{~K}\right)$

$T: \quad$ Temperature $(\mathrm{K})$

$t: \quad$ Time (s)

$u$ : Velocity component along the wall $(\mathrm{m} / \mathrm{s})$

$V: \quad$ Velocity vector $(\mathrm{m} / \mathrm{s})$

$v$ : Velocity component normal to the wall $(\mathrm{m} / \mathrm{s})$

$w^{\prime \prime \prime}$ : Volume power density $\left(\mathrm{W} / \mathrm{m}^{3}\right)$

$x$ : Coordinate component along the wall

$y$ : Coordinate component normal to the wall.

\section{Greek Letters}

$\mu$ : Absolute viscosity $(\mathrm{Kg} / \mathrm{m} \mathrm{s})$

$\rho$ : Density $\left(\mathrm{Kg} / \mathrm{m}^{3}\right)$

$\phi$ : Viscous dissipation $\left(\mathrm{J} / \mathrm{Kg} \mathrm{m}^{2}\right)$.

\section{Subscripts}

down: Bottom wall

inlet: Entrance of the wall

up: Top wall.

\section{References}

[1] B. Sunden and S. Trollheden, "Periodic laminar flow and heat transfer in a corrugated two-dimensional channel," International Communications in Heat and Mass Transfer, vol. 16, no. 2, pp. 215-225, 1989.

[2] T. Nishimura and S. Matsune, "Vortices and wall shear stresses in asymmetric and symmetric channels with sinusoidal wavy walls for pulsatile flow at low Reynolds numbers," International Journal of Heat and Fluid Flow, vol. 19, no. 6, pp. 583$593,1998$.

[3] G. Fabbri, "Heat transfer optimization in corrugated wall channels," International Journal of Heat and Mass Transfer, vol. 43, no. 23, pp. 4299-4310, 2000.

[4] G. Fabbri and R. Rossi, "Analysis of the heat transfer in the entrance region of optimised corrugated wall channel," 
International Communications in Heat and Mass Transfer, vol. 32, no. 7, pp. 902-912, 2005.

[5] C. Y. Cheng and C. C. Wang, "Forced convection in micropolar fluid flow over a wavy surface," Numerical Heat Transfer A, vol. 37, no. 3, pp. 271-287, 2000.

[6] S. Ergin, M. Ota, and H. Yamaguchi, "Numerical study of periodic turbulent flow through a corrugated duct," Numerical Heat Transfer A, vol. 40, no. 2, pp. 139-156, 2001.

[7] M. Vasudevaiah and K. Balamurugan, "Heat transfer of rarefied gases in a corrugated microchannel," International Journal of Thermal Sciences, vol. 40, no. 5, pp. 454-468, 2001.

[8] B. Niceno and E. Nobile, "Numerical analysis of fluid flow and heat transfer in periodic wavy channels," International Journal of Heat and Fluid Flow, vol. 22, no. 2, pp. 156-167, 2001.

[9] A. Ali and Y. Hanaoka, "Experimental study on laminar flow forced-convection in a channel with upper V-corrugated plate heated by radiation," International Journal of Heat and Mass Transfer, vol. 45, no. 10, pp. 2107-2117, 2002.

[10] C. Zimmerer, P. Gschwind, G. Gaiser, and V. Kottke, "Comparison of heat and mass transfer in different heat exchanger geometries with corrugated walls," Experimental Thermal and Fluid Science, vol. 26, no. 2-4, pp. 269-273, 2002.

[11] A. M. Guzman and C. H. Amon, "Transition to chaos in converging-diverging channel flows: ruelle-takens-newhouse scenario," Physics of Fluids A, vol. 6, no. 6, pp. 1994-2002, 1994.

[12] A. M. Guzman and C. H. Amon, "Dynamical flow characterization of transitional and chaotic regimes in convergingdiverging channels," Journal of Fluid Mechanics, vol. 321, pp. 25-57, 1996.

[13] A. M. Guzman and C. H. Amon, "Convective heat transfer and flow mixing in converging-diverging channel flows," in Proceedings of the ASME International Mechanical Engineering Congress and Exposition, pp. 61-68, November 1998, HTDVol. 361-1.

[14] C. C. Wang and C. K. Chen, "Forced convection in a wavy-wall channel," International Journal of Heat and Mass Transfer, vol. 45, no. 12, pp. 2587-2595, 2002.

[15] S. Savino, G. Comini, and C. Nonino, "Three-dimensional analysis of convection in two-dimensional wavy channels," Numerical Heat Transfer A, vol. 46, no. 9, pp. 869-890, 2004.

[16] M. Z. Hossain and A. K. M. Islam, "Fully developed flow structures and heat transfer in sine-shaped wavy channels," International Communications in Heat and Mass Transfer, vol. 31, no. 6, pp. 887-896, 2004.

[17] H. M. Metwally and R. M. Manglik, "Enhanced heat transfer due to curvature-induced lateral vortices in laminar flows in sinusoidal corrugated-plate channels," International Journal of Heat and Mass Transfer, vol. 47, no. 10-11, pp. 2283-2292, 2004.

[18] P. Naphon, "Laminar convective heat transfer and pressure drop in the corrugated channels," International Communications in Heat and Mass Transfer, vol. 34, no. 1, pp. 62-71, 2007.

[19] P. Naphon, "Heat transfer characteristics and pressure drop in channel with V corrugated upper and lower plates," Energy Conversion and Management, vol. 48, no. 5, pp. 1516-1524, 2007.

[20] P. Naphon, "Effect of corrugated plates in an in-phase arrangement on the heat transfer and flow developments," International Journal of Heat and Mass Transfer, vol. 51, no. 15-16, pp. 3963-3971, 2008.

[21] M. Gradeck, B. Hoareau, and M. Lebouche, "Local analysis of heat transfer inside corrugated channel," International Journal of Heat and Mass Transfer, vol. 48, no. 10, pp. 1909-1915, 2005.
[22] Y. Islamoglu and C. Parmaksizoglu, "The effect of channel height on the enhanced heat transfer characteristics in a corrugated heat exchanger channel," Applied Thermal Engineering, vol. 23, no. 8, pp. 979-987, 2003.

[23] Y. Islamoglu and A. Kurt, "Heat transfer analysis using ANNs with experimental data for air flowing in corrugated channels," International Journal of Heat and Mass Transfer, vol. 47, no. 6-7, pp. 1361-1365, 2004.

[24] Y. Islamoglu and C. Parmaksizoglu, "Numerical investigation of convective heat transfer and pressure drop in a corrugated heat exchanger channel," Applied Thermal Engineering, vol. 24, no. 1, pp. 141-147, 2004.

[25] S. Kuhn and P. R. V. Rohr, "Experimental investigation of mixed convective flow over a wavy wall," International Journal of Heat and Fluid Flow, vol. 29, no. 1, pp. 94-106, 2008.

[26] S. W. Chang, A. W. Lees, and T. C. Chou, "Heat transfer and pressure drop in furrowed channels with transverse and skewed sinusoidal wavy walls," International Journal of Heat and Mass Transfer, vol. 52, no. 19-20, pp. 4592-4603, 2009.

[27] S. W. Chang, A. W. Lees, T. M. Liou, and G. F. Hong, "Heat transfer of a radially rotating furrowed channel with two opposite skewed sinusoidal wavy walls," International Journal of Thermal Sciences, vol. 49, no. 5, pp. 769-785, 2010.

[28] M. V. Pham, F. Plourde, and S. K. Doan, "Turbulent heat and mass transfer in sinusoidal wavy channels," International Journal of Heat and Fluid Flow, vol. 29, no. 5, pp. 1240-1257, 2008.

[29] Y. Sui, C. J. Teo, P. S. Lee, Y. T. Chew, and C. Shu, "Fluid flow and heat transfer in wavy microchannels," International Journal of Heat and Mass Transfer, vol. 53, no. 13-14, pp. 27602772, 2010. 

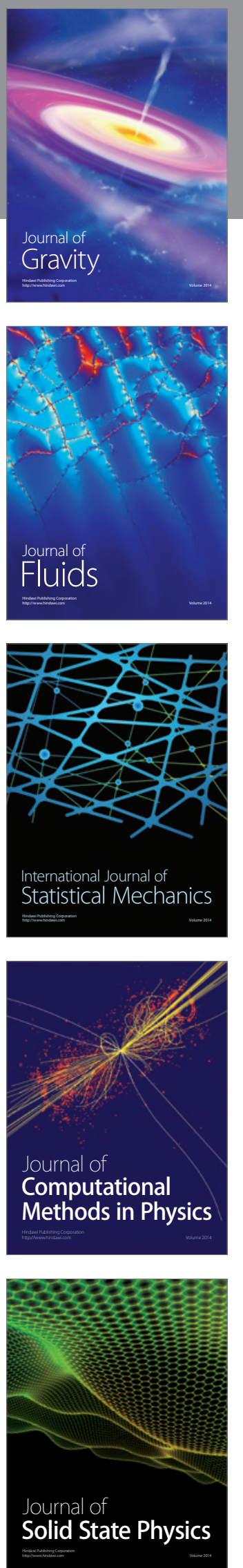

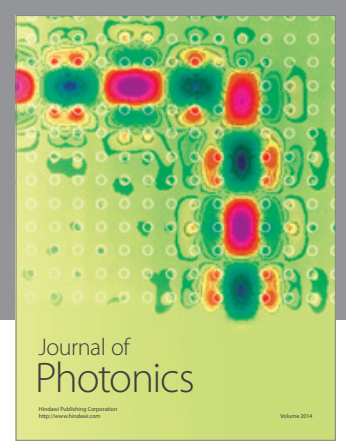

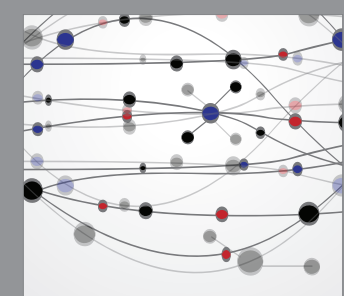

The Scientific World Journal
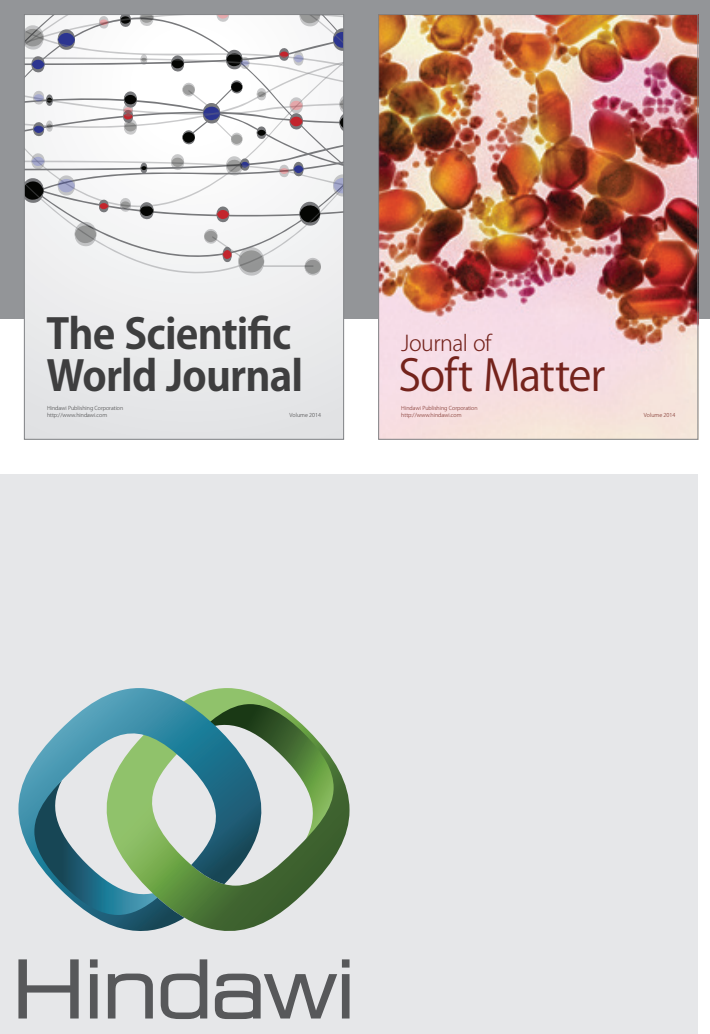

Submit your manuscripts at

http://www.hindawi.com
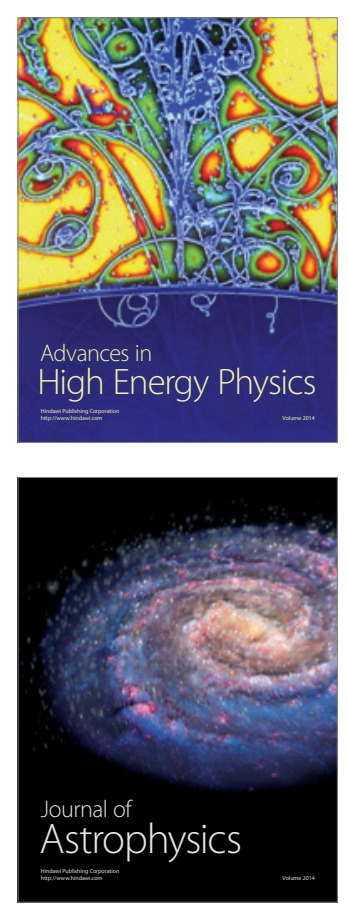
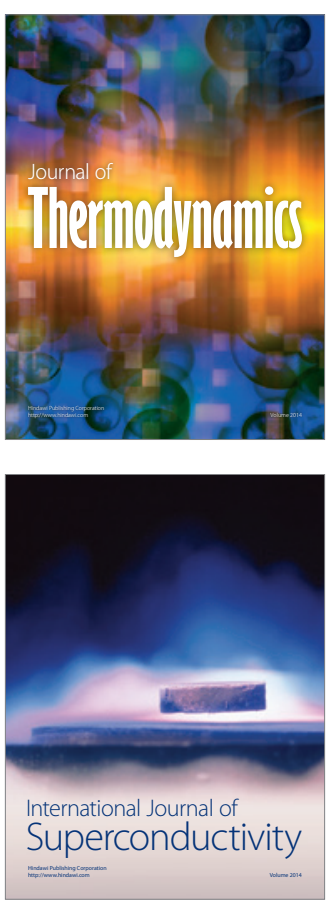
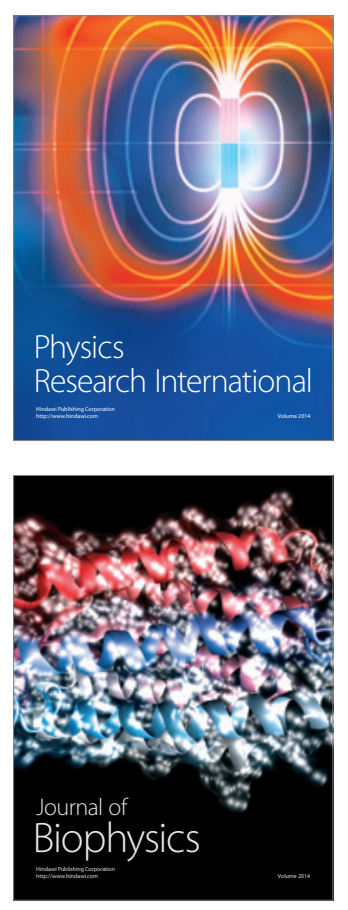
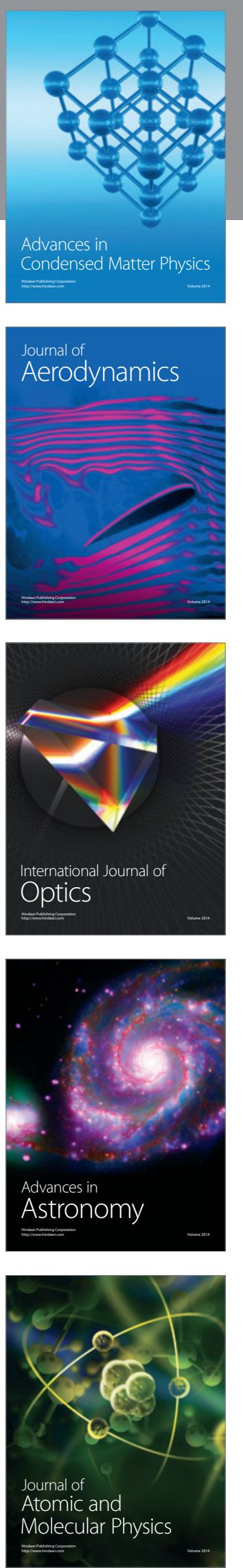